\title{
8. Schools and Theatre Pedagogies
}

\author{
Guido Di Palma and Roberta Carpani ${ }^{30}$ \\ doi.org/10.3280/oa-637-8
}

\section{Theatre and Pedagogy. An Experiential Learning Model for the Theatre in the Social Sphere}

The practices of social theatre bring into play the statutes of the theatrical institution (Bernardi, 2004 $4^{31}$; Pontremoli, 2007 and 2015) by shifting the emphasis from the performance to its processes and inevitably to those experiences of relationship and listening that are the basis of the acting techniques. Participating in a workshop or the staging of a performance in non-commercialised contexts, one can reach unknown parts of oneself and a quality in relationships with others that do not have the opacity of everyday life.

The theatre thus moves away from that oratory pulpit imagined by Diderot, where «the player $[\ldots]$ weeps as might weep an unbelieving priest preaching of the Passion» (Diderot, 1883, p. 17). In it we find, instead, the roots of a particular quality of experience that can become the seed of a regenerated humanity.

Relationships are, therefore, fundamental to rediscover the sense of a theatre pedagogy able to offer the fundamental didactic principles to those who want to use theatre as an instrument for the formation of man and therefore of society.

\section{a) For a listening pedagogy}

What is pedagogy when it comes to social theatre?

Fernand Deligny offered a suggestion by intervening on the role of the psychologist educator in post-Sixty-Eight society during a debate in Montpellier in the occupied Faculty of Literature:

I was there to say something, so I said it: what needed to be done?

Take a travelling theatre troupe and go wherever there are children placed

30 This essay was conceived together by the authors; the writing was divided as follows: paragraph 1 was written by Guido Di Palma, paragraph 2 by Roberta Carpani.

${ }^{31}$ In particular, see Claudio Bernardi's definition of social theatre (2004, p. 57). 
in institutions or homes, be a painter and have fun and pick one here, one there, a brat here two brats there ... try to discover with them [...] how to get by in existence (Deligny, [1947] 1973, p. 226 $6^{32}$ ).

In order «to get by together in existence» it is necessary to put into play, on both sides of the pedagogical relationship, an openness that goes beyond the rules. In order to go beyond mere protocol applications and reach effectiveness, social theatre interventions also require a similar condition, pushing people towards a wider openness in the relationship with themselves, others and the environment.

This is an exquisitely pedagogical problem. Which model should be chosen to optimise the results of a training process in social theatre? Is there a training model? What are the sources from which training protocols can be structured? What is the relationship between all the exercises that are part of a protocol? How do pedagogical traditions intersect? Can a training protocol be constructed from different traditions?

The reality that we live today in the field of theatre education is no longer organised poetically but pragmatically. It is therefore necessary to be aware of which training culture one wants to choose as the foundations of an intervention. The running of a laboratory, for example, requires a historical and theoretical awareness, in order to achieve a deeper understanding in the implementation of training actions, that in no case can be considered neutral, that is independent of historical and ideological processes. Today it is essential for trainers to clearly distinguish which theatrical traditions they move from. In pedagogical practices no extraterritoriality of the conductors is possible: they must be aware of the origin of the exercises they use and how they have adapted them. Finally, last but not least, what is the educational aim? Is it commensurate with the context to which it is proposed? If the aim is to change people's perception and open up horizons, another reflection by Deligny comes to mind, inspired by the group of marginalised people he took care of in 1946:

Any rehabilitation effort that is not supported by research and revolt smacks far too quickly of dirty old linen or decaying holy water. What we want for these kids is to teach them to live, not to die. To help them, not like them (Deligny, [1947] 1970, p. 207).

Research and revolt, two things that often go hand in hand, invite us to ask another essential question in the field of training: once the focus has been

32 Translator's note: translated from Italian edition as some texts differ from French original. 
identified, should the intervention model be "closed", i.e. fixed in all its parts, or "open"?

A clarification is necessary for this question to make sense. The $20^{\text {th }}$ century has taught us that in the history of theatre training there was a creative phase of pedagogy and a protocol phase; in the latter the forms experienced in the context of the birth of directing and of designing a new actor were transformed into "systems". Should conductors apply learned protocols? Or must they be "guardians of chaos", who let experiences be produced and then steer them towards solutions that take into account the different variables on the axis of the individual relationship with the participants and in the context of specific groups?

These questions cannot find easy or, even worse, unequivocal answers; rather, they serve the purpose of underlining how delicate and uncertain is the process to build a didactic path. For this reason I propose here some observations on the dialectic between revolt and didactic protocol, on which it is useful to reflect in the perspective of a social theatre pedagogy.

Radical as it may seem, we agree with Ivan Illich that «the institutionalization of values leads inevitably to physical pollution, social polarization, and psychological impotence» (Illich, 1973, p. 3). Training is first and foremost a relationship and the quality of this relationship is the foundation and the channel through which the information, or rather the facts, are put in front of the disciple by the trainer. A pedagogy that focuses on the values of the relationship, as in the case of social theatre, must necessarily put itself to the test by renouncing any advantage that institutionalisation could guarantee. This places it in the sphere of the «fourth knowledge» (Reggio, 2010, p. 164), whose essential characteristic is to operate through experiential learning and not to be «an act of depositing» (Freire, [1970] 2005, p. 72), as otherwise it would not be creative.

\section{b) The adventure of meaning}

Piergiorgio Reggio, who echoes a rich pedagogical literature linked to experiential learning, maintains that difficulties should not be removed because they represent «vital formative material, through which passes - in transformative terms - the possibility of generating learning» (Reggio, 2010, p. 71).

However, the convenience of fixing learning processes through formulas represents always a very strong temptation. If the didactic forms are kept open, this does not mean that those who participate in them cannot translate their experiences into series of exercises to be applied on other occasions. The protocol is too tempting a shortcut for teachers and learners alike, as it offers many advantages. The formalisation of the exercises is much simpler 
than the management of a process of awakening of critical consciousness $\left(\right.$ Freire $\left.^{33}\right)$. This is the problem that social theatre pedagogy has to face. How to deal with chaos? How to welcome what Barthes calls «the adventure of meaning», that is «what advenes: what comes to me from the Signifier)» (Barthes, [1985] 1994, p. 4)? It is a matter of opening up to the meaning of forms by surrendering to their logic, of letting the relationships between the notes in a melody reveal their implications without interference.

\section{c) Protocol and experience}

The rigorous codification of exercises and techniques often runs the risk of erasing the value of experience as a personal discovery. The learning of a technique cannot be confined to the mere application of exercises, as all too often happens in many theatrical contexts. On the contrary, it should develop the quality of listening to oneself and to the context, both closely related to affectivity. Feeling the effectiveness of the imitation of a gesture generates an emotional reaction and makes the gesture memorable to those who make it. In a similar pedagogical context, then, it is not at all appropriate to separate a mimetic behaviour from a transformative one, as Howard Gardner points out (Gardner, 1989). The mimetic reproduction of effective behaviour is only partially achieved by the application of a protocol. Individuals know that certain behaviours produce certain results, and satisfaction guides the repetition of effective gestures towards a transformative adaptation to the needs of their body and environment. This can also trigger a process of «awakening of critical consciousness» that, going beyond the satisfaction ensured by repetition, allows a more conscious use of the skill achieved.

Behind the techniques lies, therefore, experience. Indeed, we could consider techniques as "the repository of consolidated experience". However, in order for these experiences to be objectified and therefore transmitted without losing their life-giving function, one must not limit oneself to their protocol formulation but try to rediscover the process that determined them. In other words, if training is a system that allows specific experiences to be induced, then it is the situation, not the rule, that allows a creative and conscious attitude to be achieved.

Twentieth century theatre pedagogy taught us to open up a founding space in the teacher-student relationship. In it we find an intermediate and precarious identitarian situation between the subjects and their models, which François Jullien calls «the nowhere of the between» (Jullien, [2012]

${ }^{33}$ On the concept of critical consciousness or conscientizaçao see Freire ([1970] 2005, p. 36 and 1973). 
2014, p. 62); an atopic condition in which pupil and teacher, albeit in different ways, find themselves in the condition to operate between two shores without belonging entirely to either one or the other. In this no-man's land it becomes possible to have experiences guided by precise learning themes, but free from protocol bottlenecks and open to invention.

\section{d) To become a source}

The essential problem of social theatre pedagogy is not to transform learners into people capable of performing protocols with maximum effectiveness, but to create the skills to overcome difficulties by understanding the meaning of what is being done. This is why the quality of a pedagogical process is closely related to failure. In the field of theatre, a pedagogical process must be a safe place where mistakes can be made.

In this sense it seems to me useful to put three themes at the basis of a possible pedagogy of social theatre:

1) Students open up the didactic relationship by demonstrating in various possible ways their willingness to learn, and submit their vocation, whose essential characteristic is an active attitude to learn, to a sort of test. For this reason Plutarch compared pupils to firewood that requires kindling, rather than bottles in need to be filled (Plutarch, 1927, p. 259).

2) The teacher does not provide formulas or protocols to be applied but produces situations from which the learner's attention and processing skills are stimulated to find personal solutions. I call this learning situational (Luria) ${ }^{34}$, where experience is considered as knowledge in progress and the result of which is not the establishment of a protocol or the definition of a precise technique but a "creative openness".

3) Personal experience is the core of the pedagogical process and must produce dynamic, non-ontological knowledge. Its aim is the absorption of effective actions that cannot be defined simply in terms of techniques but rather in terms of process and discovery, because as Rilke aptly says: «Whoever pours himself out as a spring, he's known by Knowing» (1922).

\section{From Animazione Teatrale ${ }^{35}$ to Children's Theatre}

In the second half of the $20^{\text {th }}$ century, theatrical practices in school contexts in Italy underwent a reformulation which was marked by a wide phenomenon called Animazione teatrale, closely linked to the political protest movements

\footnotetext{
${ }^{34}$ On situational thinking see Luria ([1974] 1976, p. 94).

${ }^{35}$ For an explanation of the meaning of Animazione teatrale see the Notes on Translations on p. 7. The expression is used in this sense throughout the paper.
} 
that developed at the end of the 1960s and to the concurrent crisis of public theatre institutions (Rostagno, 1980; Bernardi, 2004; Perissinotto, 2004; Bernardi and Colombo, 2011). The change experienced by schools at the same time concerns first of all the role of the student: the traditional idea that the student is a passive subject, receiver of the contents of education, is contested, while the tendency to conceive education as an active and dynamic process in which the participants on both sides, teachers and students, are engaged is affirmed. In this perspective, Animazione teatrale spreads in schools, as well as elsewhere, through the tools of dramatisation (or application of theatre techniques to educational contents), through the development of children's theatre experiences, through the multiple forms of dramatic play experimented in the classroom.

While the proposal of theatrical play in schools in various European countries dates back to the period between the two world conflicts ${ }^{36}$, it should be noted that the word dramatisation appears in the ministerial programmes of the Italian primary school only in 1955 (Perissinotto, 2004). With Animazione teatrale, several novelties are experimented with: the awareness of non-verbal communication is developed; group work and audience involvement are enhanced; the work process is valued more than the exclusive orientation towards the product; the body of the pupils, usually left in the background in traditional schools, is put back into the centre of attention, recognising the inseparable connection between body and mind. As Remo Rostagno noted, the protagonists of Animazione teatrale ${ }^{37}$ went through different phases, and in particular they projected their action in schools first, and then extended it to wider territories (Rostagno, 1980). Inside the school, the question of the difference between operators of Animazione teatrale, able to use their theatrical skills with knowledge, and teacher-animators is brought up from the very beginning.

Animazione teatrale continued, within and without the school, until the end of the 1980s: the phenomenon, which was originally intended to be disruptive, was over time absorbed by the institutions and transformed into a tool to educate the population and spread culture, at the same time as, throughout the country, grassroots theatre groups proliferated alongside the bourgeois productions of repertory theatres. During these decades, theatre practices in schools made progress, but the theatre-school relationship was not institutionalised.

\footnotetext{
${ }^{36} \mathrm{We}$ cannot consider here, for lack of space, the multiple instances and occurrences of theatre in the educational systems that have appeared during more than two thousand years of history of Western theatre.

37 Among which one should mention, in addition to Rostagno, Giuliano Scabia, Franco Passatore, Loredana Perissinotto.
} 
Interwoven with Animazione teatrale, the children's theatre (Beneventi, 1994, pp. 147ff.) was born in Italy at the end of the 1960s, at the same time as in various European and Western countries the TIE (theatre in education) movement began. In Italy we observe a dichotomy which opposes children's theatre to theatre for children.

To the area of children's theatre belongs the tradition of puppets and marionettes, but very soon the children's theatre focused on young people as protagonists, their creative and expressive autonomy, the authenticity of their action, often on the borderline between improvisation and action. Gradually it developed the characteristics of a genre with its own distinctive styles (Beneventi, 1994, p. 184 ${ }^{38}$ ). The first period of relations between theatre and school ended with the 1980 s, when there was a certain closure of Italian schools with regard to theatre activities. Animazione teatrale, which as a result had remained substantially outside the school institution, was [therefore subsequently] oriented towards the social sphere, redefining its vocation and leading to art therapies.

\section{a) School theatre in the $1990 \mathrm{~s}$}

In the $1990 \mathrm{~s}$, the constant demand for theatre in educational institutions continued, finding a response in a growing range of initiatives. A significant turning point came with the Ministry of Education's interventions on the theme of theatre in schools: in addition to funding for theatre activities included in ministerial health education projects (such as the Youth Project and the Children's Project 2000), in 1995 the first Protocollo d'intesa sulle Attività di Teatro della Scuola e sull'Educazione alla Visione ${ }^{39}$ (memorandum of understanding on theatre activities in schools and vision education) between the Ministry and the Italian theatre authority ETI (Ente Teatrale Italiano), was launched (Panigada, 2000; Garavaglia, 2007). The Protocollo aimed to create an organic and stable framework in which to place theatrical activity in schools, with the recognition of the educational value of theatre and the decision to include theatre in educational processes from early childhood. The good intentions of the document did not, however, translate into operational indications and programme proposals: the issue of the possible consideration of theatre as a discipline on a par with other teaching subjects remained open.

The attention of governing bodies to theatre in school manifested itself, in

38 The genre develops in connection with the constitution of a stable market, groups grow more numerous and in 1977 the Association of Children's Theatre (ASTRA) was founded to bring them together.

${ }^{39} \mathrm{https} / /$ archivio.pubblica.istruzione.it/normativa/2007/allegati/all_prot1552.pdf 
the following years, with a sequence of documents directed to the definition of objectives, conditions and plans. The 1997, 2000, 2001 and 2006 Memoranda of Understanding added various elements: the issue of the possible educational impact of theatre languages on "ordinary" teaching practices was highlighted; universities were asked to include theatre teaching in the training processes of teachers; the opportunity was identified to create networks between operators in the different regional areas. The 2006 document on "school theatre activities and vision education», while it enhanced «theatre practice in schools» (Garavaglia, 2007, pp. 67-70), recognised the pedagogical value of theatrical workshops as a space and method in which the creative participation of young people in education could be realised. Another important point of this Memorandum was the emphasis it gave to the partnership between teacher and theatre operator as an «organic collaboration» that guaranteed the best results.

The theatre was conspicuously omitted from the school reform Law of 13 July 2015 , no. $107^{40}$, where skills and literacy for art, music, dance, media and images were discussed; but it took centre stage in the Indicazioni Strategiche per l'Utilizzo Didattico delle Attività Teatrali ${ }^{41}$, that is to say the strategic guidelines for the educational use of theatre activities issued by the Ministry for the 2016/2017 school year. The extreme novelty of the document was the recognition of theatre as an ideal didactic tool, as it allowed the perfect interaction between school and society, between educational curriculum and life. In this perspective, the practice of theatre at school was not limited, like it was the case of other arts, to the acquisition by students of artistic skills, but was proposed as a transversal pedagogical tool, able to affect profoundly the development of the individual, of the class as a group and of the school community. The Indicazioni Strategiche also proposed a pedagogy of artistic performances, consisting of the fruition of professional theatre as well as of the realisation of real performances ${ }^{42}$. Central in all the three perspectives of the theatre - intended as an ideal didactic instrument, as an artistic discipline and as acculturation -, was the concept of laboratory or active participation of the students in order to know (something), know how to do, know how to be, know how to live together.

\footnotetext{
${ }^{40} \mathrm{https}: / /$ www.gazzettaufficiale.it/eli/gu/2015/07/15/162/sg/pdf

41 https://www.miur.gov.it/documents/20182/254283/Indicazionistrategiche20162017.pdf/c0a41ae60496-4ed1-b2cf-8e060ed3bbb9?version=1.0\&t=1495630692588

42 The document reads (part two, paragraph 2): «The theatrical activities must be included in the curriculum and in the disciplinary teaching plan, if they are considered functional with respect to the objectives pursued by the teaching path. This inclusion has two macro objectives, i.e. to educate students to be both users and producers (authors, actors, directors, etc.) of performances; obviously, it is up to the teachers to make the choice of how and when to educate in or with art».
} 
Even in professional performances, one was no longer satisfied with mere enjoyment, but wanted to study, examine and discuss every work in every way. It is not surprising that the Indicazioni Strategiche ended wishing for a «harmonious and dynamic integration between "making" and "watching" the theatre»: theatre activity consists certainly in learning the languages of the art of the stage, but above all it is a place for individual growth and an instrument for building the well-being of a group. There can be no product without process.

\section{b) Open questions for competency-based schools in the $21^{\text {st }}$ century}

In his essay in this volume, Pier Cesare Rivoltella (infra, pp. 81-90) outlines the trends of the current transformation of the training paradigm: the emergence of children and young people as protagonists; the classroom conceived as a social space in which the participation of students can be developed, also as an indispensable attitude which should become a habit in their adult life; the classroom as a laboratory in which the teacher-director supports the collective work and creates the conditions for the growth of a learning choral dramaturgy. In the new school, as Bernardi(2004) recalls, at the centre there is the subject, a specific person characterised by an inseparable union of mind and body. As a consequence, education must accompany the development of the subject's freedom through a dialogical practice based on an expert combination of knowledge with competence. Some major issues of the last fifty years of theatre and school in Italy remain open, on an institutional level and from the perspective of concrete practice, even though many theatre practices in Italian schools show full awareness of the challenge of the complexity they face, often operating with little organisational, financial and planning support.

The question of the curricular and/or extracurricular nature of theatre practices in school activities remains unresolved; some stark choices are made in the process/product dichotomy which should, instead, be rethought in an integrated and non-oppositional way; collaboration in partnership between teachers and theatre operators remains an objective which is not always pursued, both for cultural reasons and for lack of financial resources; the offer of theatre practices, although wide, is still confined within the limits of extemporaneity, in the absence of its systematic placement in the educational offer of schools; the awareness that life skills and soft skills, transversal to every professional activity, can be developed through theatre practice is a fact that is still far from being fully accepted; the crucial role of 
theatre activities to reconnect schools with their localities and communities is often neglected or ignored ${ }^{43}$.

It seems quite clear that the trigger point of further developments depends on the role of teachers, protagonists of the educational relationship with students at the same time as intermediaries in the fruitful connection between schools, families and communities. Going to the source of the problem, the issue is therefore shifted in two directions: first of all, to the teachers' training, which should necessarily include a theatrical component (both as historico-critical and practical training), which is something that, at the moment, is neither systematic nor structural in the Italian university system. Secondly, and closely intertwined with the previous point, the idea of theatre that crosses our social horizon needs to be transformed, recovering its political scope, intended in its highest sense of "care of the polis", the same that, in the key stages of Western history, has always been organic with the poetic, aesthetic and cultural dimension of the theatrical experience. It is a long-term work of educational and cultural dissemination, which must necessarily become central to the objectives of academic life.

${ }^{43}$ However, there are also some virtuous cases, such as the one studied by Innocenti Malini (2011a). On the necessary connection between school and local community, see Colombo, 2001. 